\title{
O AGENTE COMUNITÁRIO DE SAÚDE NO ÂMBITO DAS POLÍTICAS VOLTADAS PARA A ATENÇÃO BÁSICA: CONCEPÇÕES DO TRABALHO E DA FORMAÇÃO PROFISSIONAL
}

THE COMMUNITY HEALTH AGENT IN THE AMBIT OF POLICIES AIMED AT BASIC HEALTH CARE: WORK AND PROFESSIONAL QUALIFICATION CONCEPTS

\author{
Márcia Valéria Morosini 1 \\ Anamaria D'Andrea Corbo 2 \\ Cátia Corrêa Guimarães 3
}

\begin{abstract}
Resumo Busca-se, aqui, reconstituir a história recente de profissionalização dos agentes comunitários de saúde no âmbito da estratégia de saúde da família, desenvolvendo a análise articulada das políticas de educação profissional e gestão do trabalho, por meio dos processos políticos desenvolvidos, das estratégias implantadas, das normatizações estabelecidas e da legislação produzida. Destacamse, ainda, a reflexão sobre o papel desempenhado pelo Ministério Público do Trabalho nesse processo e os desafios presentes no cenário político do movimento organizado desses trabalhadores, especialmente, para a Confederação Nacional dos Agentes Comunitários de Saúde, visando à efetiva realização de sua formação técnica e da regularização do acesso e da vinculação desses trabalhadores.
\end{abstract}

Palavras-chave agente comunitário de saúde; educação profissional; gestão do trabalho; formação técnica.
Abstract The goal of this article is to reconstruct the recent history of community health agent professionalization in the ambit of the family health strategy, developing articulated analyses of professional education and labor management policies via political processes that have been developed, the strategies that have been deployed, the norms that have been established, and the legislation that has been produced. This article also reflects on the Federal Labor Prosecutor's Office performance in this process and of the challenges in the political scenario of these workers' organized movement, particularly on the National Community Health Agents' Confederation, aiming at these workers' actual technical qualification and at regulating their access and employment ties.

Keywords community health agent; professional education; labor management; technical qualifications. 


\section{Introdução}

Este artigo procura resgatar e analisar as propostas de formação profissional dos agentes comunitários de saúde, bem como os projetos de regulamentação da prática profissional e da vinculação institucional desses trabalhadores. Apresentamos e analisamos as principais questões das propostas em tela, relacionando-as, buscando demonstrar que os embates relativos à natureza do trabalho, à formação requerida para o exercício profissional e à vinculação institucional desses trabalhadores estão presentes no cenário executivo e legislativo brasileiro desde a institucionalização do então Programa Nacional de Agentes Comunitários de Saúde (Pnacs), pelo Ministério da Saúde, em 1991. Vale ressaltar que, ao longo desse tempo, os agentes comunitários de saúde (ACS) se transformaram em uma força de trabalho numerosa e essencial no contexto da realização da principal estratégia de ampliação de cobertura e reformulação da atenção à saúde no Brasil, atualmente, a Saúde da Família.

Esse cenário se configura como um campo de disputa de diferentes projetos relativos às concepções de trabalho, educação e saúde. Esses embates se traduzem principalmente pela tentativa dos diversos sujeitos envolvidos - trabalhadores, gestores do SUS, centros formadores, representantes dos poderes legislativo e judiciário - de 'inflexionar' as políticas relativas à gestão do trabalho e da educação dos ACS, conforme os interesses que representam. Da correlação de forças entre esses sujeitos políticos, resultará a conformação da situação desse trabalhador, que se encontra hoje em pleno processo instituinte. A principal arena dessa disputa política tem sido o Legislativo, uma vez que as deliberações a respeito têm sido construídas em forma de lei.

Auxiliados por Silva e Dalmaso (2002, p. 15), teceremos um breve histó-rico que percorre a compreensão do ACS como "um elemento nuclear da realização de determinadas políticas de saúde, em especial de programas que expressam modelos para reorientação da assistência à saúde no país". Essa reorientação da assistência visa, principalmente, ao deslocamento da atenção à saúde - que se resume à assistência médico-curativa de ação individual - para a atenção integrada à saúde - que compreende a prevenção, a promoção e a assistência como atos contínuos de intervenção sobre a saúde e passa, necessariamente, pelo entendimento da saúde como um processo social resultante das condições de vida da população.

Esses programas partilham a experiência de instituir um trabalhador com a incumbência principal de constituir-se no elemento de ligação entre os serviços de saúde e a comunidade. Como poderemos observar, essa missão, hoje tão fortemente associada ao ACS, esteve presente em programas anteriores, de ampliação de cobertura para populações específicas. 
Restringimo-nos apenas às propostas oficiais - governamentais -, uma vez que compõem políticas públicas e expressam a participação do Estado tanto na construção da realidade sanitária brasileira quanto na instituição de uma realidade de trabalho e formação que, ao longo de décadas, contribui para que se culmine na complexidade em que se realiza a profissão de ACS no presente. Embora o mapeamento relativo à participação de diversas instituições aliadas aos movimentos populares na formação de trabalhadores com atuação na área da saúde não seja o objeto de nosso estudo, identificamos que foi notável também a atuação das instituições religiosas, sobretudo na relação com trabalhadores comunitários. David (2001) e Ramos (2007) destacam o papel das instituições católicas que, para David atuaram "numa perspectiva transformadora das relações entre profissionais e classes populares" (David, 2001, p. 62). Ramos (2007), atualmente presidente da Confe-deração Nacional de Agentes Comunitários de Saúde e também ACS em Recife, relembra que, em 1980

\begin{abstract}
"as pessoas da comunidade e um grupo técnico com destaque para padres, freiras, médicos, enfermeiras criou o Mops (Movimento Popular em Saúde), já como desdobramento de diversos trabalhos desenvolvidos nos anos 70. Na minha comunidade, tinha o Projeto Diocesano, sob a liderança de Dom Helder, que foi fundamental para a realização do I Encontro Nacional de Experiências em Saúde Comunitária em Lins em 1978 - os grupos diocesanos contavam com 700 pessoas" (Ramos, 2007, Aula inaugural).
\end{abstract}

Retomando a perspectiva das intervenções de caráter público-estatal, comecemos pelo Serviço Especial de Saúde Pública (Sesp), desenvolvido entre 1942 e 1960, e pela Fundação Serviço Especial de Saúde Pública (FSESP). O primeiro foi criado em meio à Segunda Guerra Mundial, por meio de contrato de cooperação que envolveu o Ministério de Estado de Negócios Exteriores do Brasil e representante dos interesses dos Estados Unidos, visando a preservar o aporte de matéria-prima ao grupo de países aliados em guerra - fato que explica a sua focalização na região de extração de borracha e minério de ferro. As atividades inicialmente centravam-se no saneamento e no combate às endemias locais que acometiam a população assistida, entre elas, a malária.

As atividades do Sesp ampliaram-se ao ponto de, em 1960, no âmbito do Ministério da Saúde, ser criada a FSESP, que, durante 30 anos, desenvolveu uma série de experiências de ampliação de cobertura, incluindo a assistência médica no campo da saúde pública.

Em relação a esses programas, destaca-se o trabalho de auxiliares conhecidas como visitadoras sanitárias, que atuavam, tanto na unidade de saúde quanto na comunidade, realizando visitas domiciliares, atividades de promoção da saúde, prevenção de doenças, monitoramento e acompanhamento de grupos de risco e vigilância sanitária, com supervisão e orientação do enfermeiro. 
O Piass Nordeste, como ficou conhecida a fase inicial do programa (19761979), recrutou, nas próprias comunidades a serem beneficiadas, pessoal de nível auxiliar, que era também responsável pela mobilização comunitária em torno das metas do programa: implantação de sistemas simplificados de abastecimento de água, de destino de dejetos, e do lixo; hortas, pomares, criação de animais etc. Os auxiliares eram treinados nos próprios serviços de saúde para as atividades de mobilização social.

Na década de 1980, o Piass atingiu a sua maior expansão, que correspondeu à sua etapa nacional, na qual se destacou o projeto Devale - Projeto de Expansão de Serviços Básicos de Saúde e Saneamento em Área Rural, Vale do Ribeira um braço do Piass nacional em São Paulo, especificamente para regiões de Sorocaba e Vale do Ribeira. No projeto Devale, encontramos agentes de saúde recrutados na própria comunidade, operando postos de saúde rurais e na periferia de centros urbanos, responsáveis por um conjunto de atividades comunitárias e de atenção individual.

Nessa época, já se encontravam, entre outros, os seguintes critérios de seleção: saber ler e escrever, ser maior de idade, ter boa vontade, ter tempo. Pode-mos encontrar, no projeto Devale, a descrição de preocupações quanto ao treinamento dos agentes de saúde, entre elas, a necessidade de os instrutores respeitarem as características de cada região, o desejo de que o processo de capacitação dos agentes não os afastasse de seu grupo social de origem e a indicação de que o treinamento inicial de somente dois meses deveria ter etapas posteriores garantidas, ao longo da prática nas comunidades.

Notamos que todas as experiências relatadas até aqui são referidas na obra de Silva e Dalmaso (2002), com termos tradicionalmente associados a processos formativos aligeirados que, em geral, objetivam a instrumentalização para a prática, como é o caso de 'treinamento', 'capacitação' e 'instrutores'.

É digna de nota também a afirmação, quanto ao projeto Devale, de que este propunha um modelo de treinamento que visava principalmente a "fortalecer o compromisso e a solidariedade do agente de saúde com a comunidade e prover condições para que ele/ela dispusesse do instrumental adequado e necessário para lidar com os problemas de saúde do grupo" (Silva e Dalmaso, 2002, p. 38).

Em 1987, teve início o Programa de Agentes de Saúde do Ceará, experiência inédita em dois aspectos: por ter sido a primeira vez que se trabalhou em ampla escala com os ACS e por ter transformado um plano emergencial para a seca, em que se empregavam temporariamente pessoas das regiões atingidas, em um programa de promoção da saúde, utilizando os mesmos recursos de fundos emergenciais do governo federal.

Foram contratados 6.113 trabalhadores, preferencialmente, os mais pobres, dos quais a grande maioria era de mulheres, oriundos de 118 municípios diferentes do sertão do Ceará. O treinamento realizou-se durante duas semanas como preparação para um trabalho que durou, inicialmente, entre seis e doze meses. 
Nesse segundo momento do Programa de Agentes de Saúde do Ceará, mantém-se a intenção de empregar mulheres nas regiões mais pobres do estado, buscando melhorar a condição social desse grupo.

Os agentes eram eleitos pela comunidade, alegando-se a exigência de que eles residissem na comunidade assistida e de que houvesse participação popular. O treinamento oferecido configurava-se numa capacitação inicial com duração de dois meses, a cargo da supervisão municipal, enfocando ações de educação e de promoção da participação comunitária.

Em 1991, o Ministério da Saúde criou o Programa Nacional de Agentes Comunitários de Saúde (Pnacs), institucionalizando uma série de experiências práticas em saúde que se desenvolviam em diversas regiões do país, porém de forma isolada e focal, atendendo populações em situação de maior risco à saúde. Mais tarde, em 1992, o Pnacs foi transformado em Programa de Agentes Comunitários de Saúde (Pacs), nomenclatura que permaneceu até o presente e se difundiu nacionalmente.

Inicialmente, o Pacs focalizou a questão da assistência ao grupo maternoinfantil expandindo posteriormente sua abrangência para o apoio à organização da atenção básica em saúde nos municípios. Assim, naquele momento, o elenco de ações básicas de saúde propostas para o ACS estava mais fortemente vinculado à melhoria da saúde das gestantes e crianças do que à atenção às necessidades de saúde da população como um todo. Da mesma forma, tais atividades tinham prioridade de execução em relação àquelas relacionadas à coleta e alimentação de dados primários de saúde que poderiam contribuir para a identificação das causas e determinantes das condições de saúde da população adscrita. Posteriormente, com a entrada da cólera no país, o programa passou a dar mais ênfase aos procedimentos relacionados ao controle e à prevenção desta doença.

O sucesso alcançado pelos municípios que adotaram o Pacs criou condições de possibilidade para a formulação do Programa Saúde da Família (PSF), cujas primeiras equipes começaram a ser formadas em janeiro de 1994, incorporando e ampliando a atuação dos ACS. O sucesso do Pacs foi expresso na alteração de indicadores clássicos da situação de saúde da população, principalmente a mortalidade infantil. Seus efeitos fizeram-se sentir também no aumento da cobertura vacinal e da prática do aleitamento materno exclusivo até os quatro meses de idade.

Mais tarde, o Pacs incorporou-se ao PSF e sua expansão passou a estar vinculada a este segundo programa que, por prever uma equipe constituída, no mínimo, por médico, enfermeiro, auxiliar de enfermagem e ACS, é considerado um projeto mais adequado para atender às necessidades de saúde da população. Assim, não se organiza implantação isolada do Pacs, a não ser quando for necessária uma estratégia transitória que crie condições para a implantação futura do PSF. 
Juntos, Pacs e PSF compreendem a Estratégia Saúde da Família, um conjunto de diretrizes, instrumentos e esforços articulados para viabilizar a reformulação da atenção à saúde a partir da atenção básica no marco do Sistema Único de Saúde (SUS).

Em 1997, com a publicação da portaria no 1.886, que aprova as normas e diretrizes do Pacs e PSF, foram definidas as atribuições dos ACS de modo que sua atuação estivesse centrada na promoção e prevenção de doenças, de acordo com as prioridades estabelecidas em função das necessidades de saúde identificadas no território ao qual o ACS estava vinculado (Brasil, 1997c). A portaria vedava, ao ACS, o desenvolvimento de atividades típicas do serviço interno das unidades básicas de saúde de sua referência, no intuito de fortalecer a sua inserção nas ações educativas executadas fora da unidade ambulatorial, bem como a sua participação nas atividades comunitárias.

Essas diretrizes foram atualizadas na portaria no 648, de 2006, que preservou a centralidade das atividades de prevenção e promoção da saúde na concepção do trabalho do ACS, permitindo ao agente o desenvolvimento de ações de saúde nas unidades básicas desde que vinculadas às atribuições definidas na referida portaria.

Em ambos os programas, o ACS é o trabalhador sobre o qual recaem funções estratégicas para a viabilização das metas da atenção preconizada: ser a ponte entre o serviço e a comunidade, estabelecendo aproximações e desenvolvendo vínculos com a população das comunidades atendidas. Tal perspectiva do trabalho do ACS foi reiterada em nossas pesquisas que tematizaram a compreensão de diversos atores sociais (ACS, gestores, docentes da formação) sobre a função do ACS e sua relação com a equipe de saúde (Morosini, 2001; Morosini et al., 2005).

Análises sobre o trabalho do ACS como as de David (2001) e Bornstein (2007) fortalecem a necessidade de se compreender a 'ambigüidade' que perpassa o trabalho do ACS - que, por sua vivência singular de membro de comunidade, vê seus conhecimentos de caráter popular postos em diálogo ou mesmo em contraposição com o conhecimento científico fruto das experiências de formação/profissionalização.

\section{Rumo à formação profissional}

Apesar de o ACS desenvolver um trabalho complexo, caracterizado principalmente pela dimensão educativa, em geral, a sua formação profissional tem-se caracterizado pela precariedade e diversidade, uma vez que, para essa função, desde o Pacs, o Ministério da Saúde estabelecia como critério de escolaridade as habilidades de ler e escrever. A formação profissional restringia-se em geral à capacitação em serviço, realizada pelo enfermeiro- 
supervisor, no caso do Pacs, ou pela equipe do PSF, operando-se de forma distinta nos diversos municípios que adotaram a Estratégia Saúde da Família.

A mesma portaria que estabeleceu as atribuições dos ACS - a já referida portaria no 1.886 - estabeleceu também as condições para a formação desses trabalhadores, preconizada como uma capacitação em serviço, realizada de forma continuada, gradual e permanente sob a responsabilidade do enfermeiro, com a participação dos demais membros da equipe.

Segundo Schwartz (1995), a qualificação profissional apresenta três dimensões: a conceitual, relacionada à formação e à certificação profissional; a experimental, relacionada ao conteúdo real da formação, incluindo os saberes tácitos; e a social, que insere a qualificação no âmbito das relações sociais.

Por essa perspectiva, se analisarmos as características da qualificação predominante dos ACS até o momento anterior à proposição da formação técnica, temos uma qualificação classificada, então, como de nível básico da educação profissional, portanto, não regulamentada, sem pré-requisitos e que não confere habilitação. Realizada em forma de capacitação em serviço, essa qualificação tem conteúdos que variam em função dos problemas locais, em que a avaliação pauta-se nas atividades realizadas no serviço e o material educativo estrutura-se em torno das atividades a serem realizadas.

A (não) escolarização do ACS, justificada pela necessidade de esse trabalhador ser representativo da comunidade em que atua, denota a desvalorização da dimensão conceitual de sua qualificação, o que fortalece a desvalorização social desse trabalhador, sustenta a sua baixa remuneração e contrapõe-se à pauta política por uma melhor qualificação dos trabalhadores da saúde, de uma maneira geral.

Outra perspectiva sobre a produção de mecanismos de desvalorização do trabalho do ACS é trazida por Bornstein (2007), que, em seu estudo sobre o processo de trabalho do ACS, identifica práticas de desvio de função deste trabalhador, sobretudo no sentido de responsabilizá-lo pela execução de tarefas burocráticas. Para a autora, a recorrência deste fenômeno deve nos fazer refletir sobre a desvalorização do trabalho do ACS como mediador no trabalho educativo. Acrescentamos também que o desvio de função denota a compreensão do trabalho do ACS como inespecífico e de baixa complexidade, podendo ser redirecionado, segundo as necessidades dos serviços, para atividades que supostamente exigem pouca capacitação.

A capacitação em serviço, muitas vezes também usada como estratégia para a baixa escolarização desses trabalhadores, sugere a valorização da dimensão experimental dessa qualificação, justificada na necessidade de se aproximar a escola do serviço. Porém, quando reduzida a essa dimensão, e sem a mediação das instituições cuja missão principal é o ensino, esse tipo de capacitação pode implicar a redução do conhecimento à realização de atividades e extinguir o espaço da escola em favor do serviço. 
Na gestão de José Serra no Ministério da Saúde (1998-2002), ainda no governo Fernando Henrique Cardoso, foi elaborada uma primeira proposta de formação profissional para os ACS que visava prover parâmetros nacionais para a sua profissionalização, em atenção à lei no 10.507, de julho de 2002 (Brasil, 2002).

Podemos dizer que a lei 10.507, que criou a profissão do ACS, é o resultado de vários debates sobre a vinculação e a natureza do trabalho do agente, que culminou com uma série de ações legislativas sobre o tema. Até a publicação do decreto no 3.184, de 4 de outubro de 1999, que fixou as diretrizes para o exercício da atividade do ACS, nove projetos de lei (PL) tramitaram no Congresso Nacional com o objetivo de regulamentar a prática profissional dos ACS (Corbo, Pereira e Porto, 1999).

A história recente dos ACS no Brasil é um exemplo claro da necessidade de articulação estreita entre as políticas de formação e de gestão do trabalho. Ao mesmo tempo, ilustra, de forma ímpar, as contradições e embates inerentes a essa relação.

\section{Em busca do reconhecimento profissional e da regularização dos vínculos}

De forma breve, apresentaremos algumas das indicações constantes nos projetos de regulamentação da prática dos ACS, com o intuito de demonstrar que os embates relativos à natureza do trabalho, à formação requerida para o exercício profissional e à vinculação institucional desses trabalhadores estão presentes no cenário executivo e legislativo brasileiro desde a institucionalização do Pacs, pelo Ministério da Saúde, em 1991.

A primeira iniciativa que tramitou no Congresso Nacional com a preocupação de regulamentar o exercício dos agentes foi o PL no 5.287, de 1990, de autoria de Percival Muniz (Brasil, 1990). O PL argumentava que o agente de saúde pública era um profissional que, por exercer ações educativas na comunidade, desenvolvendo atividades básicas de saúde no domicílio, possuía uma diferenciação em relação aos demais profissionais do setor. A profissão era de exclusividade daqueles que tivessem concluído o curso especializado, de seis meses de duração, com currículo definido pelo Conselho Federal de Educação. O agente deveria residir na comunidade em que fosse trabalhar, sendo por ela escolhido. O vínculo empregatício se daria em acordo com as normas constantes da Consolidação das Leis do Trabalho (CLT). Esse PL foi arquivado em 1991.

Em 1993, foi apresentado o PL no 3.994, de autoria de Paulo Portugal (Brasil, 1993). Nesse projeto, eram especificadas algumas das atividades do agente de saúde comunitária, a saber: ministrar conhecimentos sobre a prevenção de doenças, prestar atendimentos em primeiros socorros, em imu- 
nização, em cuidados primários e em vigilância epidemiológica. Era exigido o ensino fundamental completo para o exercício profissional. Com uma forte preocupação com os direitos trabalhistas desse profissional, o projeto previa o pagamento de hora extra diurna e noturna e fixava a jornada de trabalho em seis horas diárias. Foi arquivado em 1995, sem ter sido votado.

Em 1995, o texto final do PL no 332, de 1995, que continha parecer da Comissão de Seguridade Social e Família (CSSF) do Congresso Nacional4, representou significativo avanço em relação aos projetos anteriores, provavelmente pelo fato de a CSSF ter consultado, para a elaboração do substitutivo, diversas instâncias afins ao tema, como órgãos internacionais, setores do Ministério da Saúde e entidades da área de enfermagem e dos ACS (Brasil, 1995b).

Ao retomar o PL de Paulo Portugal, mantiveram-se as atividades definidas naquele, estabelecendo-se, entretanto, que o Ministério da Saúde, após consulta ao Ministério do Trabalho, regulamentaria as ações de responsabilidade do agente. Seguindo a orientação dos próprios agentes, sugeriu-se a modificação da denominação da categoria de agente de saúde comunitária para 'agente comunitário de saúde', por representar melhor a atuação desses trabalhadores. A escolaridade exigida foi reduzida à $4^{a}$ série do ensino fundamental, em contraposição a alguns projetos anteriores que fixavam a escolaridade no ensino fundamental completo. A argumentação utilizada era de que a maior parte dos agentes é oriunda dos estratos mais pobres da população, onde, pelas razões conhecidas, se tem menor possibilidade de concluir o ensino fundamental. Em contrapartida, estabelecia que o empregador deveria, em período a ser determinado, prover a complementação dessa escolaridade.

No projeto foi fixada ainda a jornada de trabalho para oito horas diárias, com o intuito de não criar exceções em relação aos demais profissionais de saúde. Entretanto, ao observar-se a especificidade de trabalho dessa categoria, sugeriu-se organização dos trabalhadores para a implementação de contrato coletivo de trabalho 5 , com vistas à melhor discussão e definição da carga horária de trabalho, bem como à definição dos procedimentos relacionados ao pagamento de horas extra.

De forma pioneira, esse projeto restringiu a atuação dos agentes exclusivamente a ambiente externo "sendo vedada atuação nos serviços laboratoriais, ambulatoriais ou hospitalares, ou como integrante de quadro de pessoal ou de equipe multidisciplinar destes setores". No relatório da CSSF, não foi dada nenhuma justificativa para esse veto. $\mathrm{O}$ projeto foi arquivado sem ter ido a plenário para votação.

Em 1997, novo PL de no 3.604, de 1997, foi apresentado à Câmara dos Deputados. Nesse projeto também foram exigidos o ensino fundamental completo e a conclusão de curso específico; foram ainda relacionadas algumas 
das atribuições do ACS (Brasil, 1997a). Todas as ações propostas fazem parte do elenco já definido pelo Ministério da Saúde no documento "Programa de agentes comunitários de saúde", publicado em 1994. O projeto definiu, pela primeira vez, a competência dos conselhos federal e regionais de enfermagem de fiscalizar a atuação profissional dos ACS. Nos projetos anteriores, a fiscalização desse profissional era de responsabilidade das prefeituras municipais através de seus órgãos de saúde. O projeto foi arquivado em fevereiro de 1999.

Nos anos de 1998 e 1999 ainda foram apresentados mais três PLs (PL no 4.868, de 1998, no 86, de 1999, e no 357, de 1999), que reproduziam algumas das questões contidas nos outros PLs anteriores.

No dia 4 de outubro de 1999, pelo decreto no 3.189, o presidente da República fixou as diretrizes para o exercício da atividade de ACS. Nesse decreto, de forma bastante ampla, definiu-se que o ACS deveria desenvolver atividades de prevenção de doenças e promoção de saúde por meio de ações individuais e coletivas, nos domicílios e na comunidade. Porém, diferente dos projetos de lei anteriores ao decreto, definiu que a supervisão do agente seria realizada por profissional competente, retirando a exclusividade da supervisão do campo da enfermagem. Atrelava também a exigência de escolaridade aos requisitos mínimos estabelecidos pelo Ministério da Saúde (Brasil, 1999c).

Finalmente, em 10 de julho de 2002, como já indicamos anteriormente, a lei 10.507 instituiu a profissão de ACS. Sobre essa lei, é necessário destacar que, além de reiterar que os agentes deveriam morar na comunidade em que atuam, como já preconizava o PSF, ela determinou que esses trabalhadores deveriam ter o ensino fundamental completo - excetuando-se os que já exerciam essa ocupação antes daquela data - e deveriam também concluir um curso de qualificação básica. Além disso, delegou ao Ministério da Saúde a responsabilidade pela definição do conteúdo programático desse curso.

\section{Onde a formação e a profissionalização se cruzam}

A lei no 10.507 teve o papel de reconhecer os ACS como uma categoria profissional e de incentivar o processo de formação desses trabalhadores. Tanto que, no ano seguinte, atendendo a essa determinação legal, na gestão de Humberto Costa no Ministério da Saúde, ainda no primeiro governo Lula, a Secretaria de Gestão do Trabalho e da Educação na Saúde (SGTES) iniciou um processo amplo de discussão de um projeto de qualificação para os ACS.

O primeiro projeto em pauta foi uma proposta de qualificação profissional de nível básico que não constituía um itinerário formativo e apresentava uma carga horária de apenas 80 horas, restringindo-se, portanto, às exigências da nova lei. 
A continuidade dessa discussão no âmbito do Ministério da Saúde ampliou-se com a participação de diversos atores, inclusive representantes das Escolas Técnicas do SUS, que passaram a discutir um perfil de competências que definisse o trabalho e a formação dos ACS. Resultou desse debate a convicção de que um curso de formação inicial, mais rápido, não daria conta da complexidade do trabalho desses profissionais. Foi construído, então, um Referencial Curricular para Curso Técnico de Agente Comunitário de Saúde, publicado em 2004 pelo Ministério da Saúde e pelo Ministério da Educação. Explicando a iniciativa de ir além da qualificação básica que recomendava a lei no 10.507, diz a apresentação do documento, assinada pelos ministros da Saúde e da Educação:

“A relevância deste trabalhador no contexto de mudanças das práticas de saúde e o papel social do Agente Comunitário de Saúde junto à população constituem a necessidade de sua formação, feita em nível técnico e reafirma a intenção governamental de associar educação profissional à elevação de escolaridade" (Brasil, 2004b, p. 6).

A proposta de formação técnica dos ACS foi organizada a partir do perfil de competências que, por sua vez, foi pactuado a partir de consulta pública organizada pela equipe técnica da Secretaria de Gestão do Trabalho e da Educação na Saúde do Ministério da Saúde, no final de 2003.

Nesse perfil, as competências atribuídas aos ACS agrupam-se em três conjuntos de habilidades, com a seguinte formulação: 1) desenvolver ações de integração entre as equipes de saúde e as populações adscritas às unidades de saúde; 2) participar das atividades de planejamento e avaliação das ações desenvolvidas pelas equipes de saúde; 3) desenvolver ações de promoção da saúde; desenvolver ações de prevenção e monitoramento dirigidas às situações de risco sanitário para a população e desenvolver ações de prevenção e monitoramento dirigidas a grupos específicos e a doenças prevalentes (Brasil, 2004b).

O referencial curricular para a formação técnica dos ACS baseou-se nessas competências para definir os três âmbitos de atuação desse trabalhador, a partir dos quais foram construídos também três módulos. O eixo integrador entre os módulos é a promoção da saúde e a prevenção de agravos que têm função de estruturar e integrar o processo formativo (Brasil, 2004b).

Em 8 de julho de 2004, a proposta de habilitação técnica para a profissão de Agente ACS foi aprovada em parecer do Conselho Nacional de Educação (CNE/CEB 19/2004, Brasil, 2004a), homologado em novembro do mesmo ano. Nesse parecer, nota-se a preocupação de que se estabeleça uma proposta formativa comprometida com a elevação concomitante da escolaridade dos ACS. Além disso, é digno de nota o reconhecimento da especifici- 
dade dessa formação que, ao mesmo tempo, valoriza o serviço enquanto espaço formativo e constrói um itinerário formativo visando à profissionalização técnica. De acordo com esse parecer, o Curso Técnico de Agente Comunitário de Saúde foi construído em itinerários formativos, definidos como "percursos formativos organizados de forma interdependente e que possibilitem uma progressão concomitante à escolarização do trabalhador" (Brasil, 2004a).

A execução dos cursos de formação técnica dos ACS fica a cargo principalmente das Escolas Técnicas do SUS (Etsus) e dos Centros Formadores de Recursos Humanos em Saúde (Cefor) que compõem a Rede de Escolas Técnicas do Sistema Único de Saúde (Retsus). Ao todo, são 36 instituições distribuídas pelos estados brasileiros. Trata-se de escolas públicas, especificamente voltadas para a área da saúde, ligadas, em sua maioria, às secretarias de saúde dos estados e municípios, cuja principal atribuição é ordenar, orientar e participar da qualificação profissional em saúde, buscando suprir a necessidade de trabalhadores qualificados para o SUS e colaborar na consolidação das políticas públicas de saúde (Reis et al., 2004). Atualmente, mais de 200 mil ACS estão em formação - em sala de aula ou em vias de começar o curso - pelas Escolas Técnicas do SUS de todo o país, num processo induzido financeiramente pelo Ministério da Saúde.

A educação profissional de nível técnico, ao ser proposta para os ACS, incide, como já vimos, sobre um contexto de formação aligeirada e abreviada, realizada geralmente em serviço, sem requisitos prévios de escolaridade ou de carga horária. Essa nova proposta nos sinaliza com um cenário futuro mais positivo para a qualificação profissional desses trabalhadores.

Ainda em 2004, a Presidência da República emitiu o decreto no 5.154, que revogou o 2.208/97 e, dentre outras coisas, instituiu a formação por itinerários. Essa nova legislação expressa, de certa forma, um novo modo de compreender a educação profissional, que deixa de priorizar os cursos rápidos e isolados do processo formativo (Brasil, 2004c). O incentivo à formação por itinerários significa, nesse contexto, que os cursos de formação inicial e continuada, mesmo aqueles com pouca carga horária, não devem ser desenvolvidos de forma totalmente independente, como um fim em si mesmo, mas, ao contrário, devem ser pensados como etapas de um caminho de formação mais ampla que o aluno poderá seguir. Significa, em última instância, que as instituições de ensino devem ter um compromisso com a continuidade da formação do aluno, reconhecida como um direito. Nesse sentido, a publicação do decreto no 5.154/2003, pouco tempo depois do lançamento dos Referenciais curriculares do ACS, mostrou que a saúde estava em sintonia com um novo projeto de educação profissional para o país.

Compreendemos que a formação técnica dos ACS por si só não é garantia de que não se incorra numa formação instrumentalizadora, agora, com o status tecnificado. Para evitar isso, é necessário que essa formação técnica 
parta do entendimento da educação como um conjunto de práticas sociais que se articulam, baseadas nas ciências, constituindo uma formação que, além de técnica, precisa ser ética e política - no sentido de se aproximar da formação humana.

Como nos ensina Marx (1978), formação humana é entendida como a expressão social do processo de conhecimento e de realização individual que transcende o nível da ação movida pelas necessidades de subsistência. Trata-se, portanto, de compreender a formação humana como expressão de um desenvolvimento individual, mas também coletivo, ou seja, uma particularização de uma forma social de existência.

\section{Desprecarização dos vínculos: um processo inconcluso}

Se a legislação educacional contribuiu para a efetivação da proposta de formação técnica dos ACS, na área da saúde houve muitas reações negativas, vindas, principalmente, dos gestores municipais. Questionava-se a validade de investir na formação técnica de profissionais que, por terem vínculos precários, não tinham garantias de permanência no SUS. Construído como reação à proposta de formação técnica, esse argumento acabou também, de forma indireta, ajudando a fomentar o debate sobre a desprecarização dos vínculos desses profissionais.

Entretanto, é necessário registrar que, em nota técnica, intitulada Considerações sobre a formação técnica do agente comunitário de saúde, o Conselho Nacional de Secretários de Saúde - Conass (Brasil, 2006c) chama atenção para a necessidade de se estabelecer uma formação desses trabalhadores compatível com a complexidade dos problemas de saúde da população. Com esse argumento, o Conass converge para o apoio à formação técnica dos ACS criticando, inclusive, as considerações sobre a relação entre formação técnica e inserção no trabalho, que associa essa formação à pressão por maiores salários. O documento destaca que tal relação pode ser considerada para qualquer função da saúde e, se levada adiante, poderia ser um argumento contra o processo de formação técnica de outras categorias como, por exemplo, o técnico de enfermagem, o que, do nosso ponto de vista, é um contrasenso diante da luta histórica por uma crescente qualificação profissional dos trabalhadores do SUS.

A batalha política e jurídica começou, de fato, em 2003, quando o Ministério Público do Trabalho (MPT) instaurou o procedimento investigatório no 160/2003 (Brasil, 2005), que visava apurar a forma de contratação dos ACS pelos municípios e estados - no Ceará, os ACS são vinculados ao governo estadual. O entendimento do MPT era de que, como 
trabalhadores finalísticos e essenciais para o funcionamento do SUS, os ACS deveriam ser servidores públicos. Para isso, defendia a realização de concurso público, reconhecido pelo inciso II do artigo 37 da Constituição Federal como a única forma de ingresso em cargo ou emprego público no Brasil, excetuando-se as nomeações por meio de gratificação. Com isso, o MPT queria, além de regularizar o vínculo, dar clareza e caráter público ao processo de seleção desses trabalhadores.

Sem capacidade de atuação nos municípios, a estratégia que o MPT encontrou para pressionar os gestores a buscarem uma solução para a situação considerada como de ilegalidade foi ameaçar impedir o repasse de recursos que o Fundo Nacional de Saúde (FNS) fazia mensalmente para os municípios pagarem os salários dos ACS. A última formalização dessa ameaça aconteceu em dezembro de 2005, por meio de uma notificação recomendatória enviada pelo MPT ao FNS.

A exigência de realização de concurso público, feita pelo MPT, no entanto, foi recebida de forma reticente por diversos setores e instituições da saúde. O impacto que isso significaria na folha de pagamento das prefeituras, dificultando o respeito à Lei de Responsabilidade Fiscal6, foi o argumento utilizado pelo Conasems, representando os interesses dos gestores. Mas o principal problema apontado por diferentes atores era o fato de, em função de seu caráter universal, dado pela Constituição, o concurso público não poder exigir que o candidato tenha residência prévia em determinada região nem que ele continue morando naquele local após a contratação. A interpretação mais recorrente era que contratar os ACS por concurso público significaria ter de abrir mão da exigência de que eles morassem na comunidade em que atuam, característica até então considerada fundamental para o sucesso do PSF por facilitar o vínculo desses trabalhadores com a comunidade. Esse problema pautou as discussões em torno da regularização dos vínculos dos ACS por muito tempo, mobilizando, inclusive, a Confederação Nacional dos Agentes Comunitários de Saúde (Conacs), na busca de uma solução alternativa.

Procurando garantir a legalidade na seleção e contratação dos ACS e, ao mesmo tempo, não prejudicar o funcionamento do PSF, foi construída a proposta de emenda constitucional no 7/03 - votada na Câmara dos Deputados e no Senado Federal e promulgada em fevereiro de 2006 - que deu origem à emenda constitucional no 51/06. A emenda acrescenta três parágrafos ao artigo 198 da Constituição Federal (Brasil, 2006c). A principal mudança contida na emenda é a criação do processo seletivo público, como alternativa ao concurso público, especificamente para o caso dos ACS e dos agentes de combate às endemias, categoria que conseguiu se fazer representar na PEC nos seus momentos finais de tramitação. 
“§ $4^{\circ}$ Os gestores locais do sistema único de saúde poderão admitir agentes comunitários de saúde e agentes de combate às endemias por meio de processo seletivo público, de acordo com a natureza e complexidade de suas atribuições e requisitos específicos para sua atuação" (Brasil, 2006c).

Como se trata de uma modalidade jurídica completamente nova, ainda não existe uma definição precisa de processo seletivo público. O texto da lei no $11.350 / 2006$ estabelece, para o processo seletivo, os mesmos princípios que o artigo 37 da Constituição Federal elenca para o concurso público.

“Art. 9o A contratação de Agentes Comunitários de Saúde e de Agentes de Combate às Endemias deverá ser precedida de processo seletivo público de provas ou de provas e títulos, de acordo com a natureza e a complexidade de suas atribuições e requisitos específicos para o exercício das atividades, que atenda aos princípios de legalidade, impessoalidade, moralidade, publicidade e eficiência" (Brasil, 2006b).

Vale ressaltar um deslocamento ocorrido durante todo esse período transcorrido até a aprovação da emenda constitucional no 51/06. A primeira proposta de emenda constitucional, elaborada pelo deputado Maurício Hands, previa exatamente as mesmas mudanças, mas modificando o artigo 37 da Constituição Federal, que apresenta os princípios de legalidade, impessoalidade, moralidade, publicidade e eficiência como norteadores da administração pública. À época, foi aprovada na Comissão de Constituição e Justiça da Câmara dos Deputados um substitutivo dessa PEC que trocou a proposição para o artigo 198, localizado na Seção II (da Saúde) da Constituição. Fazemos esse destaque porque entendemos que essa mudança representa uma preocupação de não fazer do caso específico dos ACS um precedente para a flexibilização do concurso público como forma de contratação de servidores públicos. Daí, nos parece, que o texto tenha sido modificado no trecho da Constituição que se refere à saúde, evidenciando a especificidade e exclusividade dos trabalhadores a que ele se refere.

Criando o processo seletivo público, a emenda constitucional no 51/06 garantiu que se pudesse exigir que os ACS que se candidatassem à seleção morassem na comunidade em que trabalhariam. Mas deixou em aberto a decisão sobre uma outra discussão, que acontecia paralelamente, sobre que tipo de vínculo esses profissionais teriam com os municípios. O texto da emenda, no entanto, indicava que uma lei federal deveria dispor sobre o regime jurídico e a regulamentação das atividades desses trabalhadores. Vários projetos de lei chegaram a ser escritos, mas prevaleceu a proposta do Poder Executivo, tornada pública por meio da medida provisória no 297, emitida em junho de 2006, que, dentre outras decisões, revogou a lei 
no 10.507, que criou a profissão do ACS. Aprovada na íntegra na Câmara e no Senado, a medida provisória no 297 se tornou a lei no 11.350, de 5 de outubro de 2006, que regulamenta a emenda constitucional no 51/06.

$\mathrm{O}$ artigo $8^{\circ}$ da lei no 11.350 estabelece que os ACS e agentes de endemias deverão ser contratados por vínculo CLT, exceto nos casos em que alguma lei local determinar outro regime jurídico. Trata-se de vínculo direto com os municípios - sem intermediação de organizações sociais, como vinha acontecendo em muitas regiões - mas sem direito à estabilidade e outros benefícios garantidos pelo regime estatutário. O mesmo argumento utilizado anteriormente, contra a realização de concurso público, de que era preciso garantir modos de exigir que os ACS morassem nas comunidades em que atuam, prevaleceu na definição do vínculo CLT. O parágrafo único do artigo 10 da lei determina que um ACS poderá ser demitido caso não cumpra o requisito de "residir na área da comunidade em que atuar, desde a data da publicação do edital do processo seletivo público" ou apresentar declaração falsa de residência. Essa exigência não é válida para os agentes de combate às endemias. Outros casos em que o contrato pode ser rescindido unilateralmente pela administração pública são:

“I - prática de falta grave, dentre as enumeradas no art. 482 da Consolidação das Leis do Trabalho;

II - acumulação ilegal de cargos, empregos ou funções públicas;

III - necessidade de redução de quadro de pessoal, por excesso de despesa, nos termos da lei no 9.801, de 14 de junho de 1999; ou

IV - insuficiência de desempenho, apurada em procedimento no qual se assegurem pelo menos um recurso hierárquico dotado de efeito suspensivo, que será apreciado em trinta dias, e o prévio conhecimento dos padrões mínimos exigidos para a continuidade da relação de emprego, obrigatoriamente estabelecidos de acordo com as peculiaridades das atividades exercidas" (Brasil, 2006b).

Há interpretações de que a determinação de vínculo CLT estabelecida pela lei no 11.350 tem, na prática, apenas a função indutora, porque, desde a aprovação da emenda constitucional no 19, de junho de 1998, o parágrafo $3^{\circ}$ do artigo 39 da Constituição Federal permite que, por meio de lei local, sejam estabelecidos "requisitos diferenciados de admissão quando a natureza do cargo o exigir", o que significa que municípios, estados e União podem ter trabalhadores ligados à administração pública com os dois tipos diferentes de vínculo, CLT ou estatutário.

Mas um dos maiores problemas da lei no 11.350 certamente diz respeito ao âmbito da formação. Ela reproduz exatamente os mesmos requisitos que a lei no 10.507 elencava para o exercício da função de ACS. E dois desses requisitos são a conclusão do ensino fundamental e de um curso introdutó- 
rio de formação inicial e continuada - neste último, apenas a nomenclatura foi modificada porque, após o decreto no 5.154/05, deixou de existir qualificação básica, como já assinalamos. A diferença é que, em 2002, ainda não existia o curso técnico, tal como proposto pelo Ministério da Saúde e aprovado pelo CNE, ambos em 2004.

Uma das conseqüências possíveis dessa desatualização da lei é a prevalência de uma cultura de gestão que, justificada pelos baixos recursos disponíveis para as políticas sociais, como é o caso da saúde, invista apenas o mínimo necessário para evitar a ilegalidade. Nesse caso, alguns municípios poderiam optar apenas pela formação inicial dos seus agentes, o que significaria um retrocesso em relação ao debate público e coletivo que identificou a necessidade de um curso técnico.

\section{Considerações finais}

A despeito da legislação, é preciso considerar dois fatores fundamentais. $\mathrm{O}$ primeiro é que, aprovado pelo CNE, o curso técnico de ACS é uma realidade irreversível. Portanto, qualquer discussão que ainda se apresente poderá, no máximo, dizer respeito ao financiamento dessa formação. E aqui entramos no segundo aspecto a ser levado em conta: com mais de 170 mil ACS7 em sala de aula cursando o primeiro módulo do itinerário técnico (formação inicial) nas Escolas Técnicas do SUS do Brasil, têm-se tornado cada vez mais evidente as transformações que a educação é capaz de fazer no processo de trabalho desses profissionais. Isso tem mobilizado os ACS de todo o país e feito com que a Conacs lute cada vez mais pelo direito desses trabalhadores de se tornarem técnicos. Os resultados da formação e a pressão dos ACS organizados têm sensibilizado também os gestores, levando, inclusive, alguns estados e municípios a financiarem, com recursos próprios, a continuação do itinerário formativo rumo à habilitação técnica.

A expectativa é, então, de que, ao contrário da hipótese desenhada anteriormente, a lei no 11.350 seja lembrada apenas como aquela que garantiu aos ACS o direito à desprecarização dos vínculos e, conseqüentemente, à maior dignidade no trabalho, e não como aquela que ajudou a cercear o direito desses mesmos trabalhadores a uma formação mais plena, consistente e condizente com as necessidades do SUS. 


\section{Notas}

1 Professora-pesquisadora do Laboratório de Educação Profissional em Atenção à Saúde da Escola Politécnica de Saúde Joaquim Venâncio, da Fundação Oswaldo Cruz (EPSJV/Fiocruz), Rio de Janeiro, Brasil. Mestranda em Saúde Coletiva pelo Instituto de Medicina Social da Universidade do Estado do Rio de Janeiro (IMS/Uerj). <mguima@fiocruz.br>

2 Professora-pesquisadora da Escola Politécnica de Saúde Joaquim Venâncio, da Fundação Oswaldo Cruz (EPSJV/Fiocruz), Rio de Janeiro, Brasil. Mestre em Psicossociologia de Comunidades e Ecologia Social pela Universidade Federal do Rio de Janeiro (UFRJ). <anacorbo@fiocruz.br>

3 Assessora de Comunicação da Rede de Escolas Técnicas do SUS e Coordenadora de Comunicação da Escola Politécnica de Saúde Joaquim Venâncio, da Fundação Oswaldo Cruz (EPSJV/Fiocruz), Rio de Janeiro, Brasil. Mestranda em Comunicação e Cultura pela Universidade Federal do Rio de Janeiro (UFRJ). <catiaguimaraes@fiocruz.br>

4 O parecer da CSSF foi assinado pelo então deputado Sergio Arouca, sendo elaborado por ele o próprio substitutivo ao PL original.

5 Na ausência do contrato coletivo, o PL definia um acréscimo percentual no salário sobre o valor da hora adicional trabalhada, e outro para os casos de trabalho noturno.

6 Ficou conhecida como Lei de Responsabilidade Fiscal a Lei Complementar no 101, de 4 de maio de 2000. Dentre outras coisas, determina que a despesa total com pessoal não poderá ser maior do que $50 \%$ da receita corrente líquida da União e $60 \%$ dos estados e municípios, a cada ano.

7 Dados de agosto de 2006 (Brasil, 2006a).

\section{Referências}

BORNSTEIN, Vera Joana. O Agente comunitário de saúde na mediação de saberes. 2007. Tese (Doutorado em Saúde Pública) - Escola Nacional de Saúde Pública Sergio Arouca (Ensp)/Fiocruz, Rio de Janeiro.

BRASIL. Constituição da República Federativa do Brasil. Brasília: Senado Federal, 5 dez. 1988.

Projeto de lei no 5.287, 21 jun. 1990. Regulamenta o exercício da profissão de agente de saúde pública e dá outras providências. Diário do Congresso Nacional, Brasília, 21 jun. 1990.
Projeto de lei no 3.994, 14 ago. 1993. Dispõe sobre o exercício da profissão de agente de saúde comunitária. Diário do Congresso Nacional, Brasília, 14 ago. 1993.

Ministério da Saúde. Fundação Nacional de Saúde. Programa de Agentes Comunitários de Saúde. Brasília: Ministério da Saúde, 1994. Mimeografado.

Projeto de lei no 332-A, 8 abr. 1995. Dispõe sobre o exercício da profissão de agente de saúde comunitária. Brasília: Câmara dos Deputados, 8 abr. 1995a. Mimeografado. 
Projeto de lei no 332-A de 1995. Parecer da Comissão de Seguridade Social e Família. Brasília: Câmara dos Deputados, nov. 1995b. Mimeografado.

Projeto de lei no 3.604, set. 1997. Dispõe sobre o exercício da profissão de agente comunitário de saúde e dá outras providências. Brasília: Câmara dos Deputados, set. 1997a. Mimeografado.

Decreto no 2.208, 17 abr. 1997.

Regulamenta o $\S 2^{\circ}$ do art. 36 e os arts. 39 a 42 da lei no 9.394, 20 dez. 1996, que estabelece as diretrizes e bases da educação nacional. Brasília, 1997b. Disponível em: <http://portal.mec.gov. br/setec/arquivos/pdf/DF2208_97.pdf > . Acesso em: 4 jun. 2007.

Portaria no 1.886, 18 dez. 1997. Aprovas as normas e diretrizes do Pacs e PSF. Diário Oficial [da] República Federativa do Brasil, Brasília, 19 dez. 1997c.

Projeto de lei no 4.868, 8 dez. 1998. Dispõe sobre o exercício profissional do agente comunitário de saúde. Apensado ao PL no 3.604 de 1997. Brasília: Câmara dos Deputados, 8 dez. 1998. Mimeografado.

Projeto de lei no 86, fev. 1999. Dispõe sobre o exercício profissional do agente comunitário de saúde. Brasília: Câmara dos Deputados, fev. 1999a. Mimeografado.

Projeto de lei no 357 de 1999. Dispõe sobre o exercício profissional do agente comunitário de saúde. Apensado ao PL no 86 de 1999. Brasília: Câmara dos Deputados, 23 mar. 1999b. Mimeografado.

Decreto no 3.189, 4 out. 1999. Fixa diretrizes para o exercício da atividade de agente comunitário de saúde e dá outras providências. Diário Oficial [da] República Federativa do Brasil, Brasília, 5 out. 1999c.

Lei no $10.507,10$ jul. 2002. Cria a profissão de agente comunitário de saúde e dá outras providências. Diário Oficial [da] República Federativa do Brasil, Brasília, 11 jul. 2002.

Proposta de emenda constitucional $\mathrm{n}^{\circ} 7$, de 2003. Acrescenta $\S \S 4^{\circ}, 5^{\circ}$ e $6^{\circ}$ ao art. 198 da Constituição Federal. Disponível em: <http://www.camara. gov.br/sileg/integras/363070.pdf > . Acesso em: 4 jun. 2007.
BRASIL. Conselho Nacional de Educação. Parecer CEB. Proposta de habilitação técnica para a profissão de agente comunitário de saúde. Brasília, 8 jul. 2004a. Disponível em: <http://portal.mec.gov. br/ai/index.php?option $=$ content\&task $=$ view\&id=79\&Itemid=209>. Acesso em: 4 jun. 2007.

Ministério da Saúde/Ministério da Educação. Referencial curricular para curso técnico de agente comunitário de saúde. Brasília: Ministério da Saúde, 2004b.

Decreto no 5.154, 23 jul. 2004c. Regulamenta o $\S 2$ o do art. 36 e os arts. 39 a 41 da lei no 9.394, 20 dez. 1996, que estabelece as diretrizes e bases da educação nacional, e dá outras providências.

Ministério Público do Trabalho. Procuradoria Regional do Trabalho da $10^{a}$ Região. Coordenadoria da Defesa dos Interesses Individuais Homogêneos, Coletivos e difusos. Procedimento Investigatório 0160/2003, 3 mar. 2005.

. Ministério da Saúde. Secretaria de Gestão do Trabalho e da Educação na Saúde. Relatório de Gestão do Departamento de Gestão da Educação na Saúde: ano 2005. Brasília: Ministério da Saúde, 2006 a.

Lei no 11.350, 5 out. 2006b. Regulamenta o § 5o do art. 198 da Constitui-ção, dispõe sobre o aproveitamento de pessoal amparado pelo parágrafo único do art. 20 da emenda constitucional no 51, 14 fev. 2006, e dá outras providências. Disponível em: <http://www.planalto.gov.br/ccivil_03/_Ato2004-2006/2006/Lei/L1 1350. htm>. Acesso em: 4 jun. 2007.

Conselho Nacional de Secretários de Saúde. Considerações sobre a formação do Agente Comunitário de Saúde. Nota Técnica 14/2006c. Disponível em: <http:// www.conass.org.br/admin/arquivos/NT \%2014-06.pdf>. Acesso em: 4 jun. 2007.

Emenda constitucional 51, $14 \mathrm{fev}$. 2006c. Acrescenta os $\S \S 4^{\circ}, 5^{\circ}$ e $6^{\circ}$ ao art. 198 da Constituição Federal. Diponível em: <http://www.planalto.gov.br/ccivil_03/Constituicao/Emendas/Emc/emc51. htm>. Acesso em: 4 jun. 2007

CORBO, Anamaria D'Andrea; PEREIRA, Eliane Ministro; PORTO, Marco Antonio. 
Regulamentação da Profissão de Agente Comunitário de Saúde: elementos para discussão. Relatório final. Rio de Janeiro, Secretaria de Estado de Trabalho/SetrabRJ. Centro de Desenvolvimento e Apoio a Programas de Saúde/Cedaps, 1999.

DAVID, Helena Maria Scherlomski Leal. Sentir saúde: a religiosidade como categoria metodológica no trabalho de educação em saúde junto às classes populares. 2001. Tese (Doutoramento em Saúde Pública) - Escola Nacional de Saúde Pública Sergio Arouca (Ensp)/Fiocruz, Rio de Janeiro.

MARX, Karl. Manuscritos econômicos e filosóficos e outros textos escolhidos. São Paulo: Abril Cultural, 1978. (Os pensadores).

MOROSINI, Márcia Valéria Guimarães Cardoso. O agente comunitário de saúde no marco da Estratégia Saúde da Família no município do Rio de Janeiro: desafio à formação em saúde. Relatório final de pesquisa do Programa de Aperfeiçoamento do Ensino Técnico (Paetec)/EPSJV Fiocruz/Faperj. Rio de Janeiro, nov. 2001. et al. Relatório de atividades da oficina regional de Natal. Projeto de pesquisa Material Didático para os Docentes do Curso Técnico de ACS: melhoria na Qualidade na Atenção Básica, Programa Desenvolvimento Tecnológico e Inovação em Saúde Pública - SUS. Natal, 16, 17, 18 jun. 2005.

RAMOS, Tereza. Formação técnica e desprecarização dos ACS: uma luta por cidadania. Aula inaugural. Escola Politécnica de Saúde Joaquim Venâncio/ Fiocruz, Rio de Janeiro, 4 abr. 2007. 1 CD.

REIS, Renata Cornélio et al. Trabalhar em rede: um desafio para as escolas técnicas do SUS. Trabalho, Educação e Saúde, v. 2, n. 1, p. 189-201, 2004.

SCHWARTZ, Yves. De la 'qualification' à la 'compétence'. Education Permanente, 123, p. 125-138, 1995.

SILVA, Joana Azevedo; DALMASO, Ana Silvia Whitaker. Agente comunitário de saúde: o ser, o saber, o fazer. Rio de Janeiro: Ed. Fiocruz, 2002.

Recebido em 08/01/2007

Aprovado em 21/06/2007 